\title{
Duodichogamy and ANdrodioecy in THE CHINeSE Phyllanthaceae Bridelia tomentosa ${ }^{1}$
}

\author{
Shixiao Luo, ${ }^{2,3}$ DianXiang Zhang, ${ }^{2,5}$ and Susanne S. Renner ${ }^{4}$ \\ ${ }^{2}$ South China Botanical Garden, The Chinese Academy of Sciences, Guangzhou 510650, China; ${ }^{3}$ The Graduate School of the \\ Chinese Academy of Science, Beijing, 100039, China; and ${ }^{4}$ Department of Biology, University of Munich, \\ D-80638 Munich, Germany
}

\begin{abstract}
Flowering plants commonly separate male and female function in time, but rarely are the two stages synchronized within and among individuals. One such temporal mating system is duodichogamy in which each plant produces two batches of male flowers that are temporally separated by a batch of female flowers, with within-individual synchrony and among-individual asynchrony to ensure mating partners. Duodichogamy is known only from a few species in four genera in unrelated families. We report on duodichogamy in the Chinese tree species Bridelia tomentosa (Phyllanthaceae), a common colonizer of disturbed habitats. In three populations monitored over $2 \mathrm{yr}$, most trees flowered in the order male $\rightarrow$ female $\rightarrow$ male, and resting periods between flowering bouts precluded selfing almost completely. Individuals flowered for several weeks, with the onset of flowering slightly asynchronous among trees. Pollination was by flies, and experimental pollen supplementation of a subset of a tree's flowers did not increase fruit set, suggesting high levels of insect visitation and possible resource limitation. Nineteen percent of the 166 trees monitored skipped the first male phase, and another 13\% skipped the female phase, remaining male in both years (and also a third year). The regular presence of pure males, if genetically fixed, would make $B$. tomentosa androdioecious in addition to duodichogamous. Comparison of duodichogamous taxa known so far shows that all have few ovules, fitting with the hypothesis that duodichogamy may result from male competition for access to a small supply of ovules.
\end{abstract}

Key words: androdioecy; duodichogamy; fly pollination; mating systems; Phyllanthaceae; reproductive biology.

Cross-pollinating plants are under selection to synchronize pollen export and stigma receptivity among individuals. At the same time, individuals are under selection to separate pollen release and stigma receptivity to reduce stigma clogging, pollen discounting, and selfing (Lloyd and Webb, 1986). These two selective pressures have resulted in intricate temporal sexual patterns, namely, dichogamy, duodichogamy, and heterodichogamy. The most common of these is dichogamy, which involves male and female phases that may or may not be synchronized within and among individuals (Lloyd and Webb, 1986; (Bertin and Newmann, 1993). Much rarer is heterodichogamy, which involves two genetically reciprocal morphs, one functioning as a female first, then as a male, the other behaving in the opposite way; this system is known in 18 genera from 11 families (Delpino, 1874; Gleeson, 1982; Renner, 2001; Endress and Lorence, 2004). By far the rarest temporal sexual system, however, is duodichodamy, which involves two periods of male flowering separated by a single female-flowering phase, with all flowers of a given individual in the same phase. Duodichogamy was discovered in Castanea (Fagaceae; Stout, 1928, who also coined the term duodichogamy) and is also known in Acer and Dipteronia (Sapindaceae; de Jong, 1976) and a species of sawgrass, Cladium jamaicense (Cyperaceae; Snyder and Richards, 2005). It was inferred for Bridelia retusa (L.) A. Juss. (Borges et al., 1997) but not ascertained with confidence

\footnotetext{
${ }^{1}$ Manuscript received 28 February 2006; revision accepted 11 December 2006.

The authors thank R. Q. Zhang, S. J. Li, X. F. Deng, and Y. Q. Li for assistance in the field; G. R. Zhang for identifying insects; S. Dressler for confirming the Bridelia identification; R. Borchert for discussion of data analysis; R. E. Ricklefs for help with statistics; M. Dorken, H. Schaefer, and an anonymous reviewer for critical comments; and L. Gu for help with the illustrations. The National Natural Science Foundation of China supported this project (30570314).

5 Author for correspondence (e-mail: dx-zhang@scib.ac.cn)
}

because flowering had begun before the onset of the study. Here we report results of a 2-yr project (with the monitoring of male trees continued for a third year) on the ecology of Bridelia tomentosa Blume, a treelet of disturbed vegetation in China, Malesia, and Indochina (Dressler, 1996; Forster, 1999).

Because duodichodamy is known for so few species, there is little theory about the adaptive advantages of this phenological strategy. Lloyd and Webb (1986, p. 143) in their benchmark review of temporal patterns of flowering, discussed duodichogamy as "a second type of synchronous dichogamy in which there are $1 \frac{1}{2}$ cycles in a flowering season," citing the aforementioned studies on Castanea (Stout, 1928; Jaynes, 1975) and on Acer and Dipteronia (de Jong, 1976). They went on to suggest that intrasexual selection among pollen parents should be toward increased paternal expenditure and pollen production. "Intrasexual selection usually favours floral mechanisms that increase the number of visitors that can remove pollen from each flower [...]. A simple way of making pollen available to more visitors is to extend the period of pollen presentation in a flower beyond the period when stigmas are effectively pollinated" (p. 147). Based on this, they predicted that "if dichogamy is selected because it prolongs pollen presentation, [...] protandry is the selected mode, and pollen presentation should normally extend throughout or beyond the period of stigma presentation." They continued, "There is insufficient information at present to determine how frequently these predictions are borne out"

In the $20 \mathrm{yr}$ since Lloyd and Webb's review, the empirical basis for understanding duodichogamy has been broadened by two further examples, Cladium jamaicanese (Snyder and Richards, 2005) and the aforementioned, insufficiently known Bridelia retusa (Borges et al., 1997). Based on these data, duodichogamy can occur in self-compatible species (Cladium jamaicense; Snyder and Richards, 2005) as well as in selfincompatible ones (Castanea; Jaynes, 1975), in wind-pollinated 
species (Castanea; Cladium) as well as in insect-pollinated species (Acer; de Jong, 1976), and in herbaceous species (Cladium) as well as in trees (Acer, Castanea, Dipteronia). This provides little from which to predict conditions that would favor the evolution of duodichogamy. Lloyd and Webb's (1986) suggestion that intrasexual competition among pollen parents for access to ovules remains the most convincing hypothesis but is difficult to test. One might expect that male-male competition would be negatively affected by pollinator scarcity and/or by few ovules being offered or matured into fruits. The last would be most likely in species with few ovules and plants under strong resource limitation. Bridelia tomentosa has thousands of flowers and four ovules per ovary. To assess whether fruit set in $B$. tomentosa might be pollinator or resource limited, we studied natural pollinator visits and fruit set, carried out supplemental pollinations, and monitored natural fruit abortion. We also investigated the species' ability to self via pollinator-mediated geitonogamy. Bridelia tomentosa has unisexual flowers, and selfing can only occur if flowers of a tree's male phase overlap with flowers of its female phase or vice versa.

Our investigation of $B$. tomentosa, initially guided by the hypothesis that duodichogamy implies male-male competition and should be favored by resource limitation, led to the incidental discovery of a likely new case of androdioecy, that is, the coexistence of genetic males and hermaphrodites.

\section{MATERIALS AND METHODS}

Study sites and species-In 2004 and 2005, we monitored 166 trees of Bridelia tomentosa in three natural populations in the Shaojiwo Forest Park, the Huolushan Forest Park, and on the 300-ha grounds of the South China Botanical Garden (SCBG), all near Guangzhou, Guangdong Province, southeastern China. Due to the unannounced felling of trees in 2004, only 34 trees could be monitored in both years, 56 trees were monitored only in 2004, and 76 only in 2005 . We are continuing to monitor the pure male trees and have results for eight of them for 2006 (Results, Discussion). Just before the onset of flowering, 29 (2004) and 26 (2005) treelets were permanently tagged at the SCBG site, 30 (2004) and 53 (2005) at Huolushan, and 31 (2004 and 2005) at Shaojiwo. At the SCBG site, trees were located on a small hill; other flowering trees on the garden grounds were not monitored. At the Shaojiwo and Huolushan sites, all trees on particular mountain slopes were monitored, and we may have achieved complete population sampling. The study areas have a monsoon climate, and their natural vegetation is monsoon rain forest.

Bridelia tomentosa (vouchers Luo 239, 240, and 241, deposited in the SCBG herbarium, duplicate at FR, det. S. Dressler, Aug. 2005) is a colonizer of disturbed vegetation in southern China, India, southeastern Asia, and Queensland (Li, 1994; Dressler, 1996). Fertile trees were 1-12 m tall, with stem diameters of $0.6-22.4 \mathrm{~cm}(N=63)$. Male and female flowers of $B$. tomentosa are borne in subsessile clusters; the flowers have greenish-yellow petals about $1.2 \mathrm{~mm}$ long and $1.0 \mathrm{~mm}$ wide. The anthers are yellow and have two thecae with $<0.5 \mathrm{~mm}$ long pollen sacs that open toward the flower center. The style has two linear lobes, about $0.4-0.6 \mathrm{~mm}$ long. Each ovary typically contains four ovules.

Flowering behavior, pollinators, and mating system-The sex of any open flowers on up to 20 branches per treelet (sometimes entire treelets) was monitored every $2-5 \mathrm{~d}$ (with shorter observation intervals predominating in 2005; see Results), and precise durations of male and female phases on each tree were recorded. Taller trees were climbed to confirm that flowers behaved the same over the entire plant. Individual flowers and stigma longevity were monitored closely in 20 flowers (10 male and 10 female) on five individuals over several days. Flowering stages were categorized as small buds, large buds, petals fully open, and stigmas or anthers wilting. Stigma receptivity was determined with 3-(4,5 dimethylthiazol-2-yl)-2,5-diphenyl tetrazolium bromide (MTT, M-2128, Sigma, St. Louis, Missouri, USA) as described in RodriguezRiano and Dafni (2000).

The presence of nectar was tested in previously bagged flowers, and a watery solution of neutral red was used to stain glandular tissues. Insect visits to male and female flowers were recorded during the peak flowering time, from 0800 to 1600 hours on 27 September 2004 at Shaojiwo, on 28 September 2004 at Huolushan, and on 22 October 2004 at SCBG. Every other quarter hour, inflorescences on marked branches were observed for $15 \mathrm{~min}$, and visitors and pollinators recorded. Nonsystematic observations were made throughout the flowering season. Visitors and pollinators at Shaojiwo and Huolushan were collected for identification, and pollen attached to their bodies was viewed with a scanning electron microscope. To determine whether insect pollination was necessary for fruit set, branches were enclosed in bags just before flowering.

During the middle of the flowering period, controlled cross-pollinations with pollen from pure males and pollen from hermaphrodites were carried out on five trees at SCBG (in 2004 and 2005), three trees (2004) and five trees (2005) at Shaojiwo, and three trees (2004) and five trees (2005) at Huolushan. Experiments involved a small fraction of a tree's thousands of flowers. Fruit set in experimentally pollinated flowers and controls was recorded after 15 and 30 $\mathrm{d}$, when immature and mature fruits were present.

$G$ statistics for contingency tables were calculated using the PopTools addon in the program Excel (Microsoft, Redmond, Washington, USA).

\section{RESULTS}

Flowering phenology and sexual phase patterns-Flowering began in mid to late August and lasted until early November (Fig. 1A-F). Trees that flowered relatively early in 2004 did so again in 2005, while those that flowered late did so in both years (Fig. 1A-F). Inflorescences typically opened one to three flowers a day $(N=10)$, usually early in the morning. Anther dehiscence and stigma receptivity began after the petals expanded. A typical branch produced several hundred flowers, and trees typically had 10-20 flowering branches. Female flowers remained open for $2.0 \mathrm{~d}( \pm 0.7 \mathrm{SD}, N=10)$, male flowers for $2.3 \mathrm{~d}( \pm 0.5 \mathrm{SD}, N=10)$. Stigmas remained receptive throughout anthesis. Individuals flowered between $7-$ $63 \mathrm{~d}(N=21$; Fig. 1A-F shows flowering duration of all trees), and populations flowered for 7-9 wk (2004 and 2005). Most individuals produced male flowers for the first $1-6 \mathrm{wk}$, female flowers for the next 1-3 wk, and a second batch of male flowers for the last 4-10 d of their overall flowering period. The first male phase lasted $27 \mathrm{~d}( \pm 12 \mathrm{SD}, N=21)$, the second male phase $5 \mathrm{~d}( \pm 4 \mathrm{SD}, N=21)$. Male flowers of the first and second male phases did not differ morphologically. During each sexual phase, flower numbers increased gradually, peaked for 2-7 d, and then decreased. All inflorescences of an individual behaved synchronously, while individuals in the population were somewhat out of phase with each other (Fig. 1A-F). The first male and female flowering phases were separated by a period of 2-4 d when no buds opened (Fig. 1A-F; this is more apparent in 2005 because of shorter observation intervals). The trees' second switch, from female to male, was less clear cut because of shorter inflorescence-resting periods (Fig. 1A-F).

Of the 166 trees, $22(13 \%)$ never produced a female batch of flowers. Of these, nine were observed in both years, and all of them stayed male (trees 4, 9, 13, 14, and 18 at SCBG; trees 9 and 16 at Shaojiwo; and trees 1 and 15 at Huolushan; see Fig. $1 \mathrm{~A}-\mathrm{F}$ for tree numbering). By 2006, eight trees continued to be pure males (trees 4, 14, and 39 at SCBG; trees 1, 15, 45, 53 and 61 at Huolushan); other trees had been cut down and therefore could not be monitored a third year. A log-likelihood contingency $(G)$ test showed that proportions of male and hermaphrodite trees did not differ significantly between the study populations $(G=$ $6.7, \mathrm{df}=3, P=0.084$ ), and a Kruskal-Wallis test on flowering duration of pure males vs. trees with male-female-male flowering did not detect a significant difference between the two groups (chi-square $=0.89, \mathrm{df}=1, P=0.35$ ). 

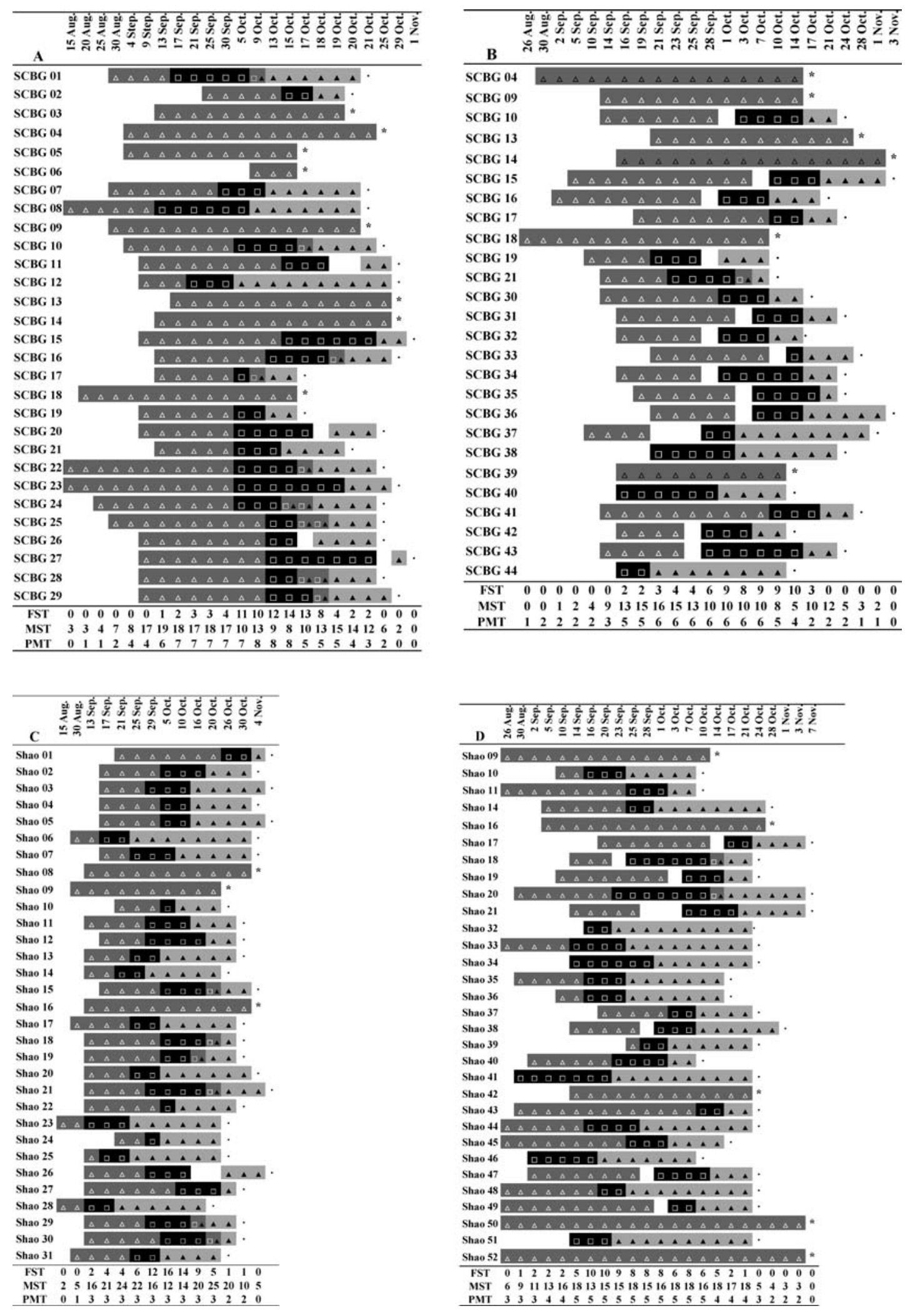

Fig. 1. Phenology of Bridelia tomentosa in the three study populations: (A) in 2004 and (B) 2005 at South China Botanical Garden, (C) in 2004 and (D) 2005 at Shaojiwo, and (E) in 2004 and (F) 2005 at Huolushan. Rows refer to consecutively numbered trees, which kept the numbers throughout the study; new trees were added in 2005 because of losses due to felling. Squares represent trees in the female phase, triangles represent trees in the first male phase, and black triangles represent trees in the second male phase. Pure male trees are marked with an asterisk. Observation intervals were shorter during peak population flowering. FST $=$ female-stage trees, MST $=$ male-stage trees, and PMT $=$ pure male trees. 

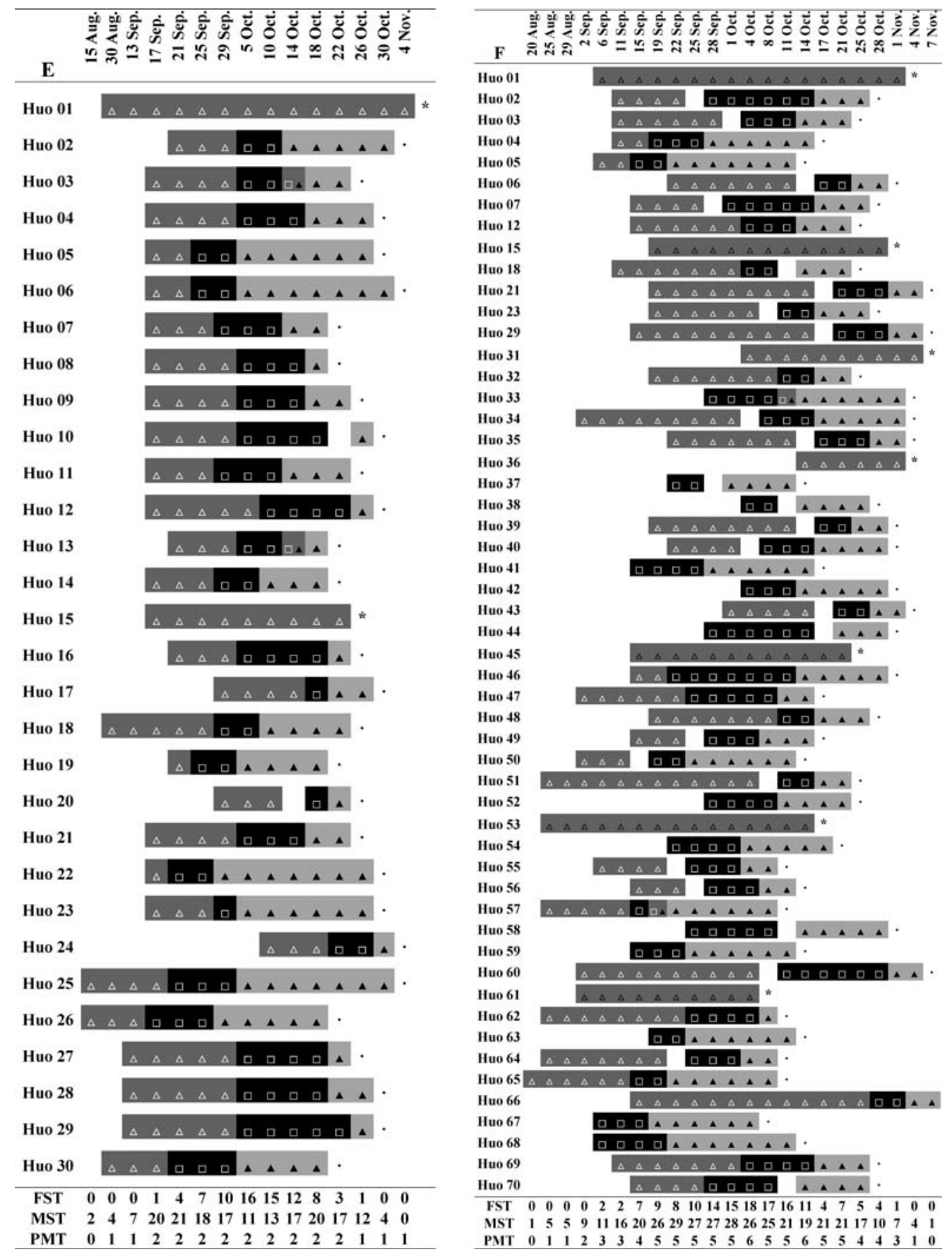

Fig. 1. Continued.

In 2005 but not 2004, 21 trees (19\% of 110 trees monitored that year) skipped the first male phase. None of these individuals were among the cohorts studied in both years. There was a marginally significant location effect, with stems from Shaojiwo being slightly larger than those from Huolushan. When location was included as an effect in an analysis of variance, stem diameter was not significantly associated $(F=$ 1.42 , df $=2,59, P=0.25$ ) with sexual phenotype (male $>$ female $>$ male; pure male; or female $>$ male).
Pollination biology-Bridelia tomentosa flowers have a spongy nectar disc (Fig. 2A, B) on which glistening nectar droplets were visible between 0700-1300 h, especially at the base of the filaments (in male flowers) and around the ovary (in female flowers). At anthesis, flowers emitted a strong, pleasant odor that attracted nectar-foraging flies, that contacted the anthers (male flower) or stigma lobes (female flower) when probing the nectar disc with their proboscises. Especially common were Atherigona soccata (Ronald), A. biseta Karl 


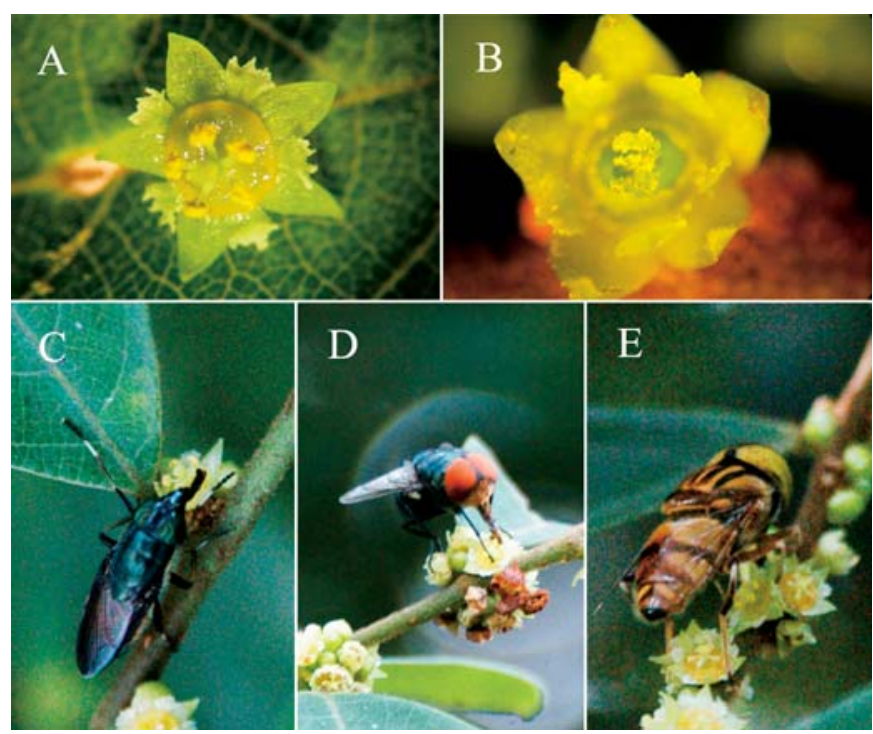

Fig. 2. Flowers (A, B) and visitors (C-E) of Bridelia tomentosa. (A) Male flower, (B) female flower, (C) Idiella euidielloides, (D) Chrysomya megacephala, and (E) Cerioidini species.

(Muscidae), Idiella euidielloides Senior-White (Fig. 2C), Chrysomya megacephala (Fab.) (Fig. 2D), Lucilia bazini Seguy (all three in the family Calliphoridae), and two species of Cerioidini (Syrphidae; Fig. 2E). These flies visited male and female flowers at all three sites, and their body surfaces, especially the foreheads, were covered with pollen of $B$. tomentosa. Individual flies typically visited several flowers on a plant, and visitation rates were highest between 0900-1200 hours.

Mating system-Fruit development began after fertilization, but remained slow until the second male flowering phase had passed its peak. After that, fruits reached maturity within about 4 wk, with growth peaking in the second to third week after pollination. At $15 \mathrm{~d}$ after anthesis, open-pollinated flowers had a mean fruit set of 43-48\% (2004) or 43-54\% (2005; Table 1). At $30 \mathrm{~d}$, fruit abortion had brought fruit set down to $36-41 \%$ (2004) or $36-49 \%$ (2005). Contingency tests showed that years and study locality had no significant effect on fruit set. Experimentally cross-pollinated flowers at $15 \mathrm{~d}$ had significantly higher fruit set than open-pollinated flowers (Table $1 ; G=20.6, \mathrm{df}=1$, $P<0.0001$ ), but at $30 \mathrm{~d}$, this difference had disappeared due to fruit abortion (Table 1; $G=3.2$, df $=1, P=0.073$ ). Bagged flowers set no fruits (Table 1). In trees in which the last female flowers overlapped with the first male flowers of the second batch (see Fig. 1A, trees 10, 16,17, 22, 24, 25, 28, and 29; Fig. 1B, tree 21; Fig. 1C, trees 15, 18, 19, 21, 29, and 30; Fig. 1D, trees 18 and 20; Fig. 1E, trees 3 and 13; Fig. 1F, trees 33 and 57), experimental geitonogamous pollinations in bagged inflorescences produced $50 \%$ fruit set, which approached the fruit set in cross-pollinated flowers, and demonstrated that $B$. tomentosa is self-compatible.

\section{DISCUSSION}

The outstanding feature of the reproductive biology of Bridelia tomentosa is its combination of duodichogamy and
TABLE 1. Fruit set in Bridelia tomentosa 15 and $30 \mathrm{~d}$ after three treatments at three sites in Guangdong Province, southeastern China (South China Botanical Garden [SCBG], Shaojiwo Forest Park, and Huolushan Forest Park) near the city of Guangzhou.

\begin{tabular}{|c|c|c|c|c|c|}
\hline \multirow[b]{2}{*}{ Treatment } & \multirow[b]{2}{*}{ Site } & \multirow[b]{2}{*}{ Year } & \multirow[b]{2}{*}{$\begin{array}{c}\text { No. flowers } \\
\text { (No. individuals) }\end{array}$} & \multicolumn{2}{|c|}{ Fruit set $(\%)$} \\
\hline & & & & $15 \mathrm{~d}$ & $30 \mathrm{~d}$ \\
\hline \multirow[t]{6}{*}{ Open pollination } & SCBG & 2005 & $74(5)$ & $39(52.7)$ & $37(50.0)$ \\
\hline & & 2004 & $200(5)$ & $91(45.5)$ & $82(41.0)$ \\
\hline & Shaojiwo & 2005 & 87 (5) & $47(54.0)$ & $41(47.1)$ \\
\hline & & 2004 & $40(3)$ & $19(47.5)$ & $15(37.5)$ \\
\hline & Huolushan & 2005 & $98(5)$ & $60(61.2)$ & $51(52.0)$ \\
\hline & & 2004 & $132(3)$ & $57(43.2)$ & 48 (36.6) \\
\hline \multirow{6}{*}{$\begin{array}{l}\text { Experimental } \\
\text { outcrossing }\end{array}$} & SCBG & 2005 & $70(5)$ & $58(82.8)$ & $43(61.4)$ \\
\hline & & 2004 & $207(5)$ & $161(77.8)$ & 93 (44.9) \\
\hline & Shaojiwo & 2005 & $57(5)$ & $43(75.4)$ & $33(57.8)$ \\
\hline & & 2004 & $102(3)$ & $61(59.8)$ & $45(44.1)$ \\
\hline & Huolushan & 2005 & $81(5)$ & $70(86.4)$ & $52(64.2)$ \\
\hline & & 2004 & $81(3)$ & $59(72.8)$ & $45(55.5)$ \\
\hline \multirow{6}{*}{$\begin{array}{l}\text { Bagged } \\
\text { inflorescences }\end{array}$} & SCBG & 2005 & $118(5)$ & 0 & 0 \\
\hline & & 2004 & $150(5)$ & 0 & 0 \\
\hline & Shaojiwo & 2005 & $90(5)$ & 0 & 0 \\
\hline & & 2004 & $40(3)$ & 0 & 0 \\
\hline & Huolushan & 2005 & $124(5)$ & 0 & 0 \\
\hline & & 2004 & $50(3)$ & 0 & 0 \\
\hline
\end{tabular}

androdioecy, with the percentage of pure males about $13 \%$. Prior to this study, duodichogamy was known in Fagaceae (Castanea; Stout, 1928; Jaynes, 1975), Sapindaceae (Acer, Dipteronia; de Jong, 1976), and Cyperaceae (Cladium; Snyder and Richards, 2005), and suspected in Bridelia retusa (Borges et al., 1997). The study on B. retusa involved 23 trees in which flowering had already started at the onset of monitoring. With the present results, Bridelia must be added to the instances of duodichogamy, with at least two species in the genus having this temporal sexual system.

That pollen-supplemented flowers did not mature more fruits than did open-pollinated flowers suggests two things. First, there were sufficient insect visits between male-phase trees (whether hermaphrodites or pure males) and female-phase trees for maximal fruit set. Indeed, at our study sites, fly visits were frequent, and several species were capable of acting as pollinators (Fig. 2C-E). Because of the strict temporal separation of pollen production and stigma presentation, $B$. tomentosa - even though self-compatible - can rarely engage in autonomous or insect-assisted selfing. Most pollination therefore involved vector-mediated outcrossing. Second, $B$. tomentosa may be resource-limited and incapable of maturing all its flowers into fruits. However, our pollen supplementation experiments only involved a small fraction of a tree's flowers and are unlikely to have substantially taxed a tree's resources. Therefore, the possibility of resource limitation in B. tomentosa needs to be tested in larger pollen supplementation experiments.

While tentative, these findings fit with Lloyd and Webb's (1986) hypothesis that duodichogamy may result from male competition for access to a small supply of ovules. The findings also fit with our hypothesis that such competition should be worst under resource limitation. In Bridelia, even though individuals produce thousands of flowers, ovaries have only four ovules, and only $36-49 \%$ of the pollinated flowers become mature fruits. Note that all other duodichogamous taxa also have few ovules: Castanea, Acer, and Dipteronia all have 
two ovules per ovary of which only one develops into a seed; Cladium has one ovule per ovary.

We envision the evolution of duodichogamy as starting from an ancestral condition of male $>$ female dichogamy; such dichogamy is documented in the genus Bridelia (Dressler, 1996). Occasional mutants then produced additional lateseason male flowers (male $>$ female $>$ male), which would be selectively favored under conditions of intrasexual competition (previous paragraph). Duodichogamy may facilitate the successful establishment of male mutants (i.e., androdioecy) because hermaphroditic, duodichogamous individuals, at least for part of their flowering time, are (phenotypic) females, which sets up conditions favoring male specialization of other individuals. Pure male trees behaved consistently over $3 \mathrm{yr}$ (2004, 2005, 2006), suggesting a genetic basis. However longer monitoring is required to confirm that androdioecy in $B$. tomentosa is genotypic, not phenotypic.

The documentation of duodichogamy and likely androdioecy in Bridelia raises the question of evolutionary pathways between the various sexual systems found in Bridelia. The Asian branch of the genus includes 19 species of shrubs and trees (Dressler, 1996; Forster, 1999). Most species are thought to be monoecious and dichogamous, but some Australian species may be dioecious (Forster, 1999). Species of Bridelia (including $B$. tomentosa) in molecular phylogenies form a clade that is sister to, or embedded in, the Asian genus Cleistanthus, both being part of a large clade of dioecious and monoecious Phyllanthaceae (Kathriarachchi et al., 2005). The small Asian clade of Bridelia therefore would provide an excellent system, similar to Acer and Mercurialis, in which possible pathways between androdioecy, dichogamy, and duodichogamy could fruitfully be investigated. At the same time, this fifth case of duodichogamy known in the flowering plants illustrates just how much remains to be learned about synchronization within and among conspecifics, especially in tropical plants (Lloyd and Webb, 1986; Bertin and Newman, 1993; Li et al., 2001; Renner, 2001; Endress and Lorence, 2004; Snyder and Richards, 2005; Borchert et al., 2005).

\section{LITERATURE CITED}

Bertin, R. I., ANd C. M. Newman. 1996. Dichogamy in angiosperms. Botanical Review 59: 112-152.
Borchert, R., S. S. Renner, Z. Calle, D. Navarrete, A. Tye, L. Gautier, R. Spichiger, and P. von Hildebrand. 2005. Photoperiodic induction of synchronous flowering near the equator. Nature 433: 627-629.

Borges, R. M., H. Somnanthan, and S. Mali. 1997. Alternations of sexes in a deciduous tree: temporal dioecy in Bridelia retusa. Current Science 72: 940-944.

DE JonG, P. C. 1976. Flowering and sex expression in Acer L.: a biosystematic study. Mededelingen Landbouwhogeschool Wageningen 76-2: 1-201.

DelPiNo, F. 1874. Ulteriori osservazioni e considerazioni sulla dicogamia nel regno vegetale. Appendice. Dimorfismo nel noce (Juglans regia) e pleiontismo nelle piante. Atti della Sociedade Italiana di Scienze Naturali 17: 402-407.

Dressler, S. 1996. The genus Bridelia Willd. (Euphorbiaceae) in Malesia and Indochina: a regional revision. Blumea 41: 263-331.

EndRess, P. K., AND D. H. LoRence. 2004. Heterodichogamy of a novel type in Hernandia (Hernandiaceae) and its structural basis. International Journal of Plant Sciences 165: 753-763.

Forster, P. 1999. A taxonomic revision of Bridelia Willd. (Euphorbiaceae) in Australia. Austrobaileya 5: 405-419.

GLEeSON, S. K. 1982. Heterodichogamy in walnuts: inheritance and stable ratios. Evolution 36: 892-902.

JAYNeS, R. A. 1975. Chestnuts. In J. Janick and J. N. Moore [eds.], Advances in fruit breeding, 490-503. Purdue University Press, West Lafayette, Illinois, USA.

Kathriarachchi, H., P. Hoffmann, R. Samuel, K. J. Wurdack, and M. W. CHASE. 2005. Molecular phylogenetics of Phyllanthaceae inferred from five genes (plastid $r b c L, a t p B, 3^{\prime} n d h F$, matK, nuclear $P H Y C$ ). Molecular Phylogenetics and Evolution 36: 112-134.

LI, P. T. 1994. Flora reipublicae popularis sinicae. Science Press, Beijing, China.

Li, Q.-J., Z.-F. Xu, W. J. Kress, Y.-M. XIA, L. Zhang, X.-B. DenG, J.-Y. GAO, AND Z.-L. BAI. 2001. Flexible style that encourages outcrossing. Nature 410: 432.

Lloyd, D. G., and C. J. WebB. 1986. The avoidance of interference between the presentation of pollen and stigmas in angiosperms. I. Dichogamy. New Zealand Journal of Botany 24: 135-162.

Renner, S. S. 2001. Heterodichogamy, how common is it? Trends in Ecology and Evolution 16: 595-597.

Rodriguez-Riano, T., and A. Dafni. 2000. A new procedure to assess pollen viability. Sexual Plant Reproduction 12: 241-244.

SNyder, J. M., and J. H. Richards. 2005. Floral phenology and compatibility of sawgrass, Cladium jamaicense (Cyperaceae). American Journal of Botany 92: 736-743.

Stout, A. B. 1928. Dichogamy in flowering plants. Bulletin of the Torrey Botanical Club 5: 141-153. 